\title{
Mobile Apps as Medical Devices
}

\author{
Vincenzo Della Mea ${ }^{1}$, Fabrizio Chiarizia ${ }^{2}$, Omar Vuattolo ${ }^{1}$ \\ ${ }^{1}$ Dept. of Mathematics and Computer Science, University of Udine, Italy \\ ${ }^{2}$ A.S.S. n.6 "Friuli Occidentale", Pordenone, Italy
}

\begin{abstract}
Background: In 2007, the European Parliament and Council amended the previous version of its directive on medical devices, allowing software to be by its own a medical device.

Objectives: Aim of the present paper is to discuss the above mentioned issue when applied to mobile apps, and to tentatively apply medical devices classification rules to a sample of apps.

Methods: Medical devices can be assigned to four different classes (I, Ila, Ilb, III) depending on their invasivity, clinical risk, duration of the contact with the body, and active or passive devices. Guidelines have been released regarding classification of software. We identified a sample of apps in Android Store (categories: Medical and Health\&Fitness) suitable for such classification, and attempted to apply the above mentioned rules.
\end{abstract}

Results: Among the 80 selected apps, 32 resulted not being classifiable as medical devices (40\%), 20 as class I (25\%), 26 as class Ila (32.5\%), and 2 as class IIb (2.5\%). If we look at ratings and number of downloads as a measure of apps usefulness, it seems like class II apps are slightly more useful than class I apps.

Conclusions: It seems that a fair amount of present apps could be subject to medical device classification, and these of higher category (and thus higher risk) are those possibly more interesting for users. This pushes for some attention towards them, not necessarily in terms of ruling, but at least of clear identification of functions and limitations.

\section{Keywords}

Mobile Applications, Medical Device Legislation

\section{Correspondence to:}

\section{Vincenzo Della Mea}

Dept. of Mathematics and Computer Science, University of Udine Address: Via delle Scienze 206 - 33100 Udine Italy

E-mail: vincenzo.dellamea@uniud.it

EJBI 2015; 11(3):en22-en27

received: November 14, 2014

accepted: Januarz 13, 2015

published: April 20, 2015

\section{Introduction}

A device is defined as medical if it is an instrument, an apparatus, an implant, an in-vitro reagent, or similar or a related article that is used to diagnose, prevent, or treat disease or other conditions, and which does not achieve its principal intended action in or on the human body by pharmacological, immunological or metabolic means (the latter action being the basis for medicinal products). Almost every country has some classification scheme to describe medical devices in classes related to the potential risks that could derive from their use. Here we will deal with the European Directive on Medical Devices ([1]) as an example, since main points are similar among regulations.

In 2007, the European Parliament and Council amended [1] the previous version of its directive on medical devices 2] to take into account some novel needs in the field. Among the various amendments, at least one is crucial for computer science researchers and software systems developers: while in the previous directive software appeared only considered as a possible part of a more complex device, in the latter version software may be by its own a medical device, as reported in the premises:

"It is necessary to clarify that software in its own right, when specifically intended by the manufacturer to be used for one or more of the medical purposes set out in the definition of a medical device, is a medical device." However, "Software for general purposes when used in a healthcare setting is not a medical device."

One consequence of this is that stand alone software is defined as active device: "Any medical device operation of which depends on a source of electrical energy or any source of power other than that directly generated by the human body or gravity and which acts by converting this energy. (...) Stand alone software is considered to be an active medical device."

Furthermore, software is intended to be subject to state-of-the art development and maintenance practices: "For devices which incorporate software or which are med- 


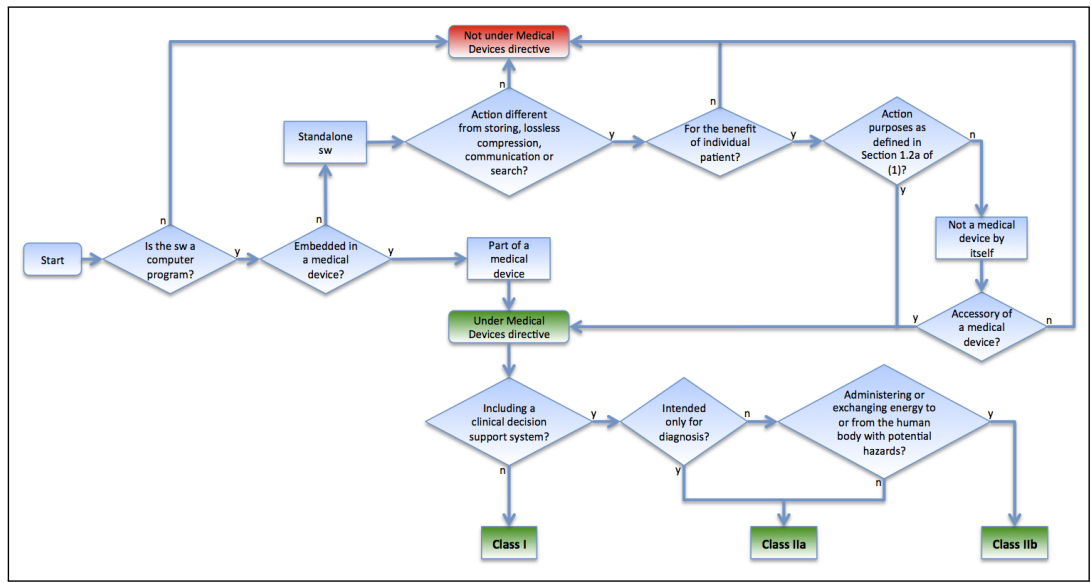

Figure 1: A decision diagram to assist qualification of software as medical device 7 .

ical software in themselves, the software must be validated according to the state of the art taking into account the principles of development lifecycle, risk management, validation and verification." The decision diagram in Figure 1 better clarifies whether a software may be classified as medical device.

The most recent amendment proposal ([3]) include some further detail regarding software. First of all, there is a generic reference to the fact that it "shall be designed and manufactured to remove or reduce as far as possible and appropriate the risk associated with the possible negative interaction between software and the environment within which it operates and interacts."

More important for the aim of present paper are the next two points. A first note is related to the technical aspects of software running on mobile systems: "Software intended to be used in combination with mobile computing platforms shall be designed and manufactured taking into account the specific features of the mobile platform (e.g. size and contrast ratio of the screen) and the external factors related to their use (varying environment as regards to level of light or noise)."

Finally, lay persons are recognised as possible users of medical devices, and there is an article ("18. Protection against the risks posed by medical devices intended by the manufacturer for use by lay persons") describing the practices to be followed for medical devices aimed at them. Among the provisions:

- the device should be easy to use by the intended user,

- it should reduce as far as possible the risk of error,

- it shall, where reasonably possible, include a procedure by which the lay person can verify that, at the time of use, the device will perform as intended by the manufacturer, and if applicable, is warned if the device has failed to provide a valid result.

In the recent years, the availability of smartphones and tablets is driving to so-called "m-Health" (Mobile Health) applications, based on phones, short text messaging, mobile web access, up to the most recent smartphone and tablet applications 4. There are growing research efforts [5] but also growing concerns about their safety and effectiveness [6].

Aim of the present paper is to discuss the above mentioned classification of software as medical device when applied to health-related mobile apps, and to tentatively apply classification rules to a sample of apps.

\section{Software as Medical Device}

Medical devices include a large array of health-related entities ranging from bandages to highly complex systems like Magnetic Resonance Imaging. They can be assigned to four different classes (I, IIa, IIb, III) depending on their clinical risk, invasivity, duration of the contact with the body, and active or passive devices. Classes range from low (I) to potentially high risk (III). Rules for classification, described in Annex IX of the directive [1, define the boundaries of the categories. Classification is based only on the intended purpose as described by the manufacturer.

A device is invasive if it penetrates inside the body, either through a body orifice or through the surface of the body. By definition, software is not invasive, although it could be part of an invasive device. Duration of contact, when relevant, can be transient (less than 60 minutes), short term (less than 30 days) or long term (more than 30 days of continous use). An active medical device depends on a source of electrical energy or any source of power other than that directly generated by the human body or gravity and which acts by converting this energy. By definition, standalone software qualifying as medical device is also active.

Depending on class, different rules apply regarding notification, declaration of conformity, surveillance, etc. Since stand alone software is not invasive but is an active device, this drives its classification. On the other side, software that is accessory to other medical devices functioning automatically falls into the category of the host 
device. In fact, guidelines have been released regarding classification of software [7, including a flowchart that helps in deciding how to classify. Let's now look at the main classification rules for software.

One decisional rule to establish whether software is or not a medical device is: "Step 3: if the software does not perform an action on data, or performs an action limited to storage, archival, communication, simple search? or lossless compression it is not a medical device."

Thus, apps aimed only at collecting data and possibly presenting them may easily be excluded from the definition. Instead, "Software which is intended to create or modify medical information might be qualified as a medical device. If such alterations are made to facilitate the perceptual and/or interpretative tasks performed by the healthcare professionals when reviewing medical information, the software could be a medical device."

Another rule (Decision Step 4) is about software for the benefit of individual patients. This software is intended to be used for the evaluation of patient data for supporting or influencing the medical care (thus software that aggregates data is excluded - e.g. software for statistics of epidemiology).

Finally, if the software is specifically intended to provide one or more of the features stated in the definition of medical device (diagnosis, monitoring, treatment, etc), it is a medical device.

Further rules help in identifying whether stand-alone software can be considered an In Vitro Diagnostic medical device (IVD), when used in support to in vitro diagnosis systems. Stand alone software that meets the definition of a medical device shall be considered as an active medical device, so that rules 9, 10, 11 and 12 of Annex IX [2] may apply:

- software as therapeutical device fall into class IIa or IIb. One reported example is insulin dosage planning stand alone software, which can be easily recognised as a possible feature of a mobile app.

- Software intended for diagnosis or therapy falls again oin IIa or IIb. Again, an interesting example is software for the presentation of the heart rate or other physiological parameters.

- Other usages fall into class I.

In practice, if a software encloses a medical decision support component, it is classified as IIa or IIb. Class III is for long term invasive medical devices and thus it does not seem applicable, as now, to software.

Since we are interested in medical apps running on regular mobile devices like smartphones and tablets, even when connected to other medical devices like sensors, from now on we will focus attention on stand alone software.

\begin{tabular}{|c|c|c|c|c|}
\hline app & free & rating & $\mathrm{d} / \mathrm{l}$ & class \\
\hline ACLS $\operatorname{sim} 2012$ & no & 4.2 & 7500 & - \\
\hline Acupressure & no & 4.3 & 30000 & - \\
\hline $\begin{array}{l}\text { ATLS Trauma Guide- } \\
\text { lines Manual }\end{array}$ & no & 5 & 300 & - \\
\hline $\begin{array}{l}\text { Blood Pressure Diary } \\
\text { Pro }\end{array}$ & no & 4.3 & 7500 & $\mathrm{I}$ \\
\hline Blood Pressure Pro & no & 4.4 & 750 & IIa \\
\hline Esame di stato & no & 4.7 & 750 & - \\
\hline Fast Infusion Dosage & no & 4.6 & 750 & IIb \\
\hline First Aid Kit & no & 4.7 & 300 & - \\
\hline $\begin{array}{l}\text { In Case of Emergency } \\
\text { (ICE) }\end{array}$ & no & 4.2 & 75000 & - \\
\hline $\begin{array}{lll}\begin{array}{l}\text { MedCalc } \\
\text { plete }\end{array} & 3000 & \text { com- } \\
\end{array}$ & no & 3.4 & 75000 & IIa \\
\hline Medical Encyclopedia & no & 3.7 & 3000 & - \\
\hline Medical mobile & no & 4.1 & 750 & - \\
\hline $\begin{array}{ll}\text { Menstrual } & \text { Calendar } \\
\text { Premium } & \\
\end{array}$ & no & 4.4 & 75000 & IIa \\
\hline MiCuroDaMe & no & 3 & 300 & - \\
\hline Muscle trigger & no & 4.4 & 30000 & - \\
\hline Pediatri & no & 4.1 & 300 & - \\
\hline Pill Organizer Pro & no & 4.5 & 300 & - \\
\hline Pocket Lab Values & no & 4.3 & 7500 & - \\
\hline $\begin{array}{l}\text { Prontuario farmaceu- } \\
\text { tico }\end{array}$ & no & 3.6 & 750 & - \\
\hline Sleep Diary Pro & no & 4.3 & 3000 & $\mathrm{I}$ \\
\hline 3D Anatomy Learning & yes & 4.3 & 300000 & - \\
\hline $\begin{array}{l}\text { Adv. Real Blood Press } \\
\text { Calc }\end{array}$ & yes & 3.8 & 300000 & I \\
\hline $\begin{array}{lll}\text { Blood } & \text { Pressure } & \text { (My } \\
\text { Heart) } & & \\
\end{array}$ & yes & 4.1 & 3000000 & IIa \\
\hline $\begin{array}{ll}\text { Doctissimo } & \mathrm{Ma} \\
\text { Grossesse } & \end{array}$ & yes & 4.3 & 300000 & $\mathrm{I}$ \\
\hline $\begin{array}{l}\text { Electrocardiogram } \\
\text { ECO Types }\end{array}$ & yes & 3.9 & 750000 & - \\
\hline Emogas PRO & yes & 4.3 & 30000 & IIa \\
\hline $\begin{array}{l}\text { Farmaci in Pronto Soc- } \\
\text { corso }\end{array}$ & yes & 4.7 & 30000 & $\mathrm{IIb}$ \\
\hline Farmacia di turno & yes & 3.9 & 750000 & - \\
\hline Gravidanza Mia Free & yes & 4 & 75000 & - \\
\hline Improve EyeSight & yes & 4.1 & 300000 & IIa \\
\hline Medscape & yes & 4.4 & 3000000 & - \\
\hline My Menstrual Diary & yes & 3.9 & 300000 & IIa \\
\hline $\begin{array}{l}\text { My Ovulation Calcula- } \\
\text { tor }\end{array}$ & yes & 3.8 & 750000 & IIa \\
\hline Myopia Exercise & yes & 3.6 & 3000 & IIa \\
\hline myPill BC Reminder & yes & 4.3 & 300000 & $\mathrm{I}$ \\
\hline Organs 3D (Anatomy) & yes & 4.1 & 30000 & - \\
\hline $\begin{array}{l}\text { Prontuario Farmaceu- } \\
\text { tico SSN }\end{array}$ & yes & 3.8 & 75000 & - \\
\hline SmartPharma Lite & yes & 4.4 & 300000 & - \\
\hline $\begin{array}{l}\text { URIGHT Tempera- } \\
\text { ture Manager }\end{array}$ & yes & 2.7 & 30000 & $\mathrm{I}$ \\
\hline Weight Calories Watch & yes & 3.8 & 30000 & I \\
\hline
\end{tabular}

Table 1: Medical apps. 
Table 2: Health and Fitness apps.

\begin{tabular}{|c|c|c|c|c|}
\hline app & free & rating & $\mathrm{d} / 1$ & class \\
\hline Abs Workout PRO & no & 4.6 & 30000 & - \\
\hline$\overline{\text { BikeComputer Pro }}$ & no & 4.7 & 30000 & $\mathrm{I}$ \\
\hline Conta Calorie Italiano & no & 3.8 & 3000 & IIa \\
\hline Daily Workouts & no & 4.4 & 30000 & - \\
\hline Diet Points Diary & no & 4.3 & 300 & IIa \\
\hline Dukan Diet & no & 3.9 & 30000 & IIa \\
\hline $\begin{array}{ll}\text { Endomondo } & \text { Sports } \\
\text { Tracker Pro } & \\
\end{array}$ & no & 4.5 & 750000 & $\mathrm{I}$ \\
\hline Freeletics & no & 4.1 & 30000 & - \\
\hline Garmin Fit & no & 3.5 & 30000 & $\mathrm{I}$ \\
\hline $\begin{array}{l}\text { HIT Interval Workout } \\
\text { Pro }\end{array}$ & no & 4.4 & 30000 & - \\
\hline $\begin{array}{lll}\text { iDukan Dukan Diet } \\
\text { Tracker }\end{array}$ & no & 4.1 & 7500 & $\mathrm{I}$ \\
\hline Instant Heart Rate Pro & no & 4.4 & 300000 & I \\
\hline Just 6 Weekds & no & 4.7 & 300000 & - \\
\hline My Diet Coach Pro & no & 4.6 & 75000 & IIa \\
\hline $\begin{array}{l}\text { QuitNow! PRO: Stop } \\
\text { Smoking }\end{array}$ & no & 4.5 & 30000 & I \\
\hline Runtastic PRO & no & 4.6 & 750000 & IIa \\
\hline Smart Alarm Clock & no & 4 & 7500 & IIa \\
\hline Stop Smoking & no & 4.3 & 30000 & - \\
\hline WomanLog Pro & no & 4.7 & 300000 & IIa \\
\hline Yoga.com Studio & no & 4.4 & 3000 & - \\
\hline Accupedo Pedometer & yes & 3.9 & 3000000 & $\mathrm{I}$ \\
\hline $\begin{array}{ll}\text { Aquafresh } & \text { Nurdle } \\
\text { Time } & \end{array}$ & yes & 3.7 & 75000 & - \\
\hline $\begin{array}{l}\text { BMI Calculator } \\
\text { Weight Loss }\end{array}$ & yes & 4 & 7500000 & IIa \\
\hline $\begin{array}{l}\text { Bunnys Period Calen- } \\
\text { dar/Tracker }\end{array}$ & yes & 4.4 & 750000 & IIa \\
\hline $\begin{array}{l}\text { Calorie Counter - My- } \\
\text { FitnessPal }\end{array}$ & yes & 4.7 & 30000000 & IIa \\
\hline Cardiograph & yes & 3.9 & 30000000 & IIa \\
\hline $\begin{array}{l}\text { Daily Butt Workout } \\
\text { FREE }\end{array}$ & yes & 4.4 & 3000000 & - \\
\hline Hydro Drink Water & yes & 4.5 & 750000 & I \\
\hline $\begin{array}{l}\text { La tua dieta personal- } \\
\text { izzata }\end{array}$ & yes & 4.3 & 750000 & IIa \\
\hline $\begin{array}{ll}\text { LifeSum } & \text { Calories } \\
\text { Counter } & \end{array}$ & yes & 4.1 & 3000000 & IIa \\
\hline Monitor Your Weight & yes & 4.4 & 750000 & IIa \\
\hline My Tracks & yes & 4.3 & 30000000 & $\mathrm{I}$ \\
\hline $\begin{array}{lll}\text { Noom } & \text { Weight } & \text { Loss } \\
\text { Coach } & & \end{array}$ & yes & 4.3 & 30000000 & $\mathrm{I}$ \\
\hline $\begin{array}{lll}\text { Period } & \text { Calendar / } \\
\text { Tracker } & & \end{array}$ & yes & 4.7 & 30000000 & IIa \\
\hline $\begin{array}{l}\text { Real Blood } \text { Pressure } \\
\text { (BP) Calc. }\end{array}$ & yes & 3.6 & 300000 & $\bar{I}$ \\
\hline $\begin{array}{l}\text { RunKeeper GPS Track } \\
\text { Run Walk }\end{array}$ & yes & 4.4 & 30000000 & IIa \\
\hline Runtastic Heartrate & yes & 4.4 & 3000000 & IIa \\
\hline $\begin{array}{ll}\text { Take } & \text { Temperature } \\
\text { Fever? } & \\
\end{array}$ & yes & 3.1 & 30000 & $\mathrm{I}$ \\
\hline Water Your Body & yes & 4.4 & 3000000 & $\mathrm{I}$ \\
\hline Workout Trainer & yes & 4.3 & 7500000 & - \\
\hline
\end{tabular}

\section{An Experiment: Matching of Currently Available Apps with the EU Classification of Medical Devices}

We wanted to verify whether the issue of classifying apps as medical devices it is actually valid in the present reality, made of few platforms with their own apps and app stores. For this, we identified a sample of apps in principle suitable for such classification, and attempted to apply the above mentioned rules.

\subsection{Material and Methods}

We focused on the Google Play store for Android devices. While apps are sold also on iTunes Store for IOs devices, and, on smaller numbers, on Windows Store for Windows devices, often apps are available for all platforms. Thus, analyzing just one store is not a limitation.

To obtain a sample of apps candidates for a possible classification as medical devices, we identified two suitable categories available on the store: Medical and Health $\&$ fitness.

Inside the above mentioned categories, we analysed in detail the 20 most popular free apps and the 20 best selling paid apps, for a total of 80 apps. Table 1 shows the selected apps in the medical category, Table 2 those pertaining to Health \& Fitness.

For each app, we collected from the store the average user rating (a user expressed judgment ranging from 1 to 5 stars and often accompanied by a review) and the number of downloads (the range categories published in the store: 500-1000, 1000-5000, 5000-10000, etc). To estimate the average number of downloads, we assigned each category the middle number of downloads for its class (e.g., 500-1000 becomes 750). We then examined the app and applied the above mentioned classification rules, assigning each app to no, I, IIa or IIb. When in doubt, we attempted to be uniform in our classification decision.

\subsection{Results}

Among the 80 apps, 32 resulted not being classifiable as medical devices (40\%), 20 as class I (25\%), 26 as class IIa $(32.5 \%)$, and 2 as class IIb (2.5\%) (Table 3 .

Table 3: Apps per free/for sale and per class.

\begin{tabular}{|l||ccccc|}
\hline Free? & no & I & IIa & IIb & Total \\
\hline \hline For sale & 21 & 8 & 10 & 1 & 40 \\
\hline Free & 11 & 12 & 16 & 1 & 40 \\
\hline Total & 32 & 20 & 26 & 2 & 80 \\
\hline
\end{tabular}

If examining separately the two store categories, it can be noted that in the medical category there are less medical devices than in the Health \& fitness category (Table 4 . Some examples of apps per class are: 
- not a medical device: health information apps, drug databases (without decision support);

- I: calculator apps, e.g., how much water to drink, with alerts, pill reminders, etc.;

- IIa: diet supporting apps that personalize diet basing on weight, age, gender, lifestyle and adapt it according to modifications; ovulation/menstruation calculators;

- IIb: only two apps have been classified this way, and both help to calculate infusion rate in critical care, emergency and urgent therapies.

While some aims seem typically classified as medical (e.g., blood pressure tracking, drugs related apps, pill reminders, etc) and some as health \&fitness (e.g., diet and physical activity apps), some other apparently equivalent apps can be found in both categories, thus suggesting that the distinction between the two categories is most likely arbitrary.

Table 4: Apps per category and per class.

\begin{tabular}{|l||ccccc|}
\hline Category & no & I & IIa & IIb & Total \\
\hline \hline Health \& Fitness & 10 & 13 & 17 & 0 & 40 \\
\hline Medical & 22 & 7 & 9 & 2 & 40 \\
\hline Total & 32 & 20 & 26 & 2 & 80 \\
\hline
\end{tabular}

While our classification attempt shall not be taken as a definitive evaluation of those apps, it suggests that in fact medical and fitness apps indeed pose an issue in terms of their effect on the human body, and thus there is some need for, at least, their evaluation from this point of view.

If we look at ratings as a measure of apps usefulness, it seems like class II apps (including both IIa and IIb due to the low numerosity of the latter) are slightly more useful than class I apps. This is reflected also in the estimated average number of downloads, that seem higher for class II apps (Figure 2).

\section{Discussion}

Although our analysis is limited in terms of sample size, it seems that a fair amount of present apps could be subject to medical device classification. Furthermore apps of category II (and thus higher risk than I, since classes are related to potential hazard) are those possibly more interesting for users. This asks for some attention towards them, not necessarily in terms of ruling, but at least of clear identification of functions and limitations.

A seminal effort in the ruling direction has been done by the Commissione Regionale Dispositivi Medici of the Emilia Romagna Region in Italy 9, which also identified a number of apps that have been already certified by either FDA or EC under the above mentioned rules. A lighter approach towards the development of a sort of "identity card" for medical apps has been instead proposed by Bonacina et al [10, where the focus is on a clear identification of features aimed at users (but possibly also at rulers in need of understanding what an app really does).

Since it is likely that medical devices are even more frequent in apps aimed at specific users, e.g., chronic diseases patients, we plan to expand our analysis on a previously collected sample of apps for diabetic patients [8], which may provide further insights on this issue.

The classification as medical device could identify a way for ruling apps safety at least from a technical point of view, although it may easily become too restrictive for small developers. In fact, FDA started efforts towards regulation of medical apps [1] and a survey of stakeholders evidentiated the following suggestions [12]

- Clarify the difference between a medical app and a wellness app;

- Clarify the difference between diagnosing and monitoring;

- Establish the risk-level threshold for FDA enforcement;

- Define the limits of the FDA's rule on apps that serve as device accessories;

- Make a plan for how to handle "modular" apps.

These suggestion act in the direction of recognising what is really medical and what is more related to wellbeing in the heterogenous world of health-related apps, and can be certainly applied to the European situation too. In fact, EU recently started a consultation on this very specific topic, aimed at collecting opinions on safety, privacy, interoperability and legislation related to mobile apps [13.

\section{Conclusion}

The presented approach has been applied to medical apps, intended as software that runs on mobile platforms, but this is not the only way of realizing the same behaviour. In particular, Web 2.0 sites are nowadays fully fledged applications, able to do everything it can be done with a programming language. Nevertheless,they are yet commonly considered as web pages, for which no rules are apparently available except volunteer codes of conduct that in principle provide an ethical standard for web publishers, like HONcode [14. It should however be noted that, among the examples in [7, software modules on servers might be qualified in their own right as medical devices depending on their intended purpose. This will open regulation to web-based apps too.

Since the classification as medical device is based on the intended purpose, that is in our case, how the app function is marketed, any too rigid regulation attempt might drive to mislabeling the software. This may be done for example by presenting it as educational even if the true purpose is diagnostic or therapeutic. 


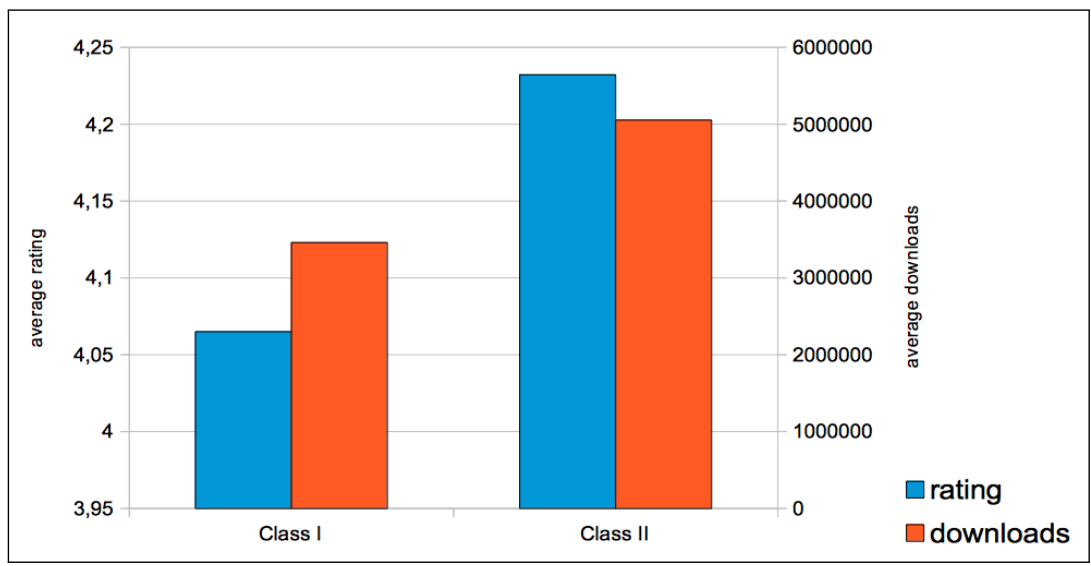

Figure 2: Average ratings and downloads for Class I and Class II apps.

This kind of issue might have driven FDA in his decision of relaxing attention on some app categories that by definition are medical devices but presumably pose low risks [15]. For these apps, FDA will in fact exercise enforcement discretion, that is, no real regulation. Examples include apps that help patients self-manage their disease or conditions without providing specific treatment or treatment suggestions; Provide patients with simple tools to organize and track their health information; diet and physical activity trackers/helpers, etc. On the other side, FDA will regulate apps that transform a mobile device into something equivalent to traditional medical devices, like drug dosage calculators and planners.

While the above mentioned relaxed approach sounds appropriate, the absumption of low risk is however a crucial point. To transform it to some more operational criterium for identifying whether an app can be hazardous or not, maybe a framework for applications risk assessment like the one suggested by Lewis and Wyatt [15] can be useful to formally characterize the possible risks connected to app categories. This might in turn provide a more evidence-based approach to medical app safety, similarly to what occurs for medicines.

\section{References}

[1] European Parliament And Council. Directive 2007/47/EC amending Council Directive 90/385/EEC on the approximation of the laws of the Member States relating to active implantable medical devices, Council Directive 93/42/EEC concerning medical devices and Directive 98/8/EC concerning the placing of biocidal products on the market. Official Journal of the European Union L247:21, 2007

[2] European Council. Directive 93/42/EEC concerning medical devices. Official Journal of the European Union L169:1, 1993

[3] European Parliament And Council. Proposal for a regulation of the European Parliament and of the Council on medical devices, and amending Directive 2001/83/EC, Regulation (EC) No 178/2002 and Regulation (EC) No 1223/2009, 2012. Available from: http://ec.europa.eu/health/medical-devices/ files/revision_docs/proposal_2012_542_en.pdf

[4] World Health Organization. mHealth: New horizons for health through mobile technologies, 2011. Available from: http: //www.who.int/goe/publications/ehealth_series_vol3/en
[5] Fiordelli M, Diviani , Schulz PJ. Mapping mHealth Research: A Decade of Evolution. J Med Internet Res 2013 (May 21); 15(5):e95

[6] McCartney M. How do we know whether medical apps work? BMJ. 2013;346:f1811.

[7] European Commission, DG Health and Consumer. Guidelines On The Qualification And Classification Of Stand Alone Software Used In Healthcare Within The Regulatory Framework Of Medical Devices. MEDDEV 2.1/6 January 2012

[8] Vuattolo O, Francescato MP, Della Mea V, Accardo A. A smartphone application for preventing exercise-induced glycemic imbalances in type 1 diabetic patients. Studies in Health Technology and Informatics 2012;180:1035-9

[9] Commissione Regionale Dispositivi Medici. M-Health e linee di indirizzo sull?utilizzo delle applicazioni medicali per dispositivi "mobile". 2013. Available from: http://www.saluter.it/ documentazione/leggi/regionali/linee-guida/m-health_ linee_applicazioni_medicali_2013.pdf

[10] Bonacina S, Marceglia S, Pinciroli F. A Pictorial Schema for a Comprehensive User-oriented Identification of Medical Apps. Methods Inf Med. 2014 May15;53(3):208-24.

[11] FDA: Mobile Medical Applications - Guidance for Industry and Food and Drug Administration Staff. 2013. Available from: http://www.fda.gov/downloads/medicaldevices/ deviceregulationandguidance/guidancedocuments/ ucm263366.pdf

[12] E. Strickland. The FDA Takes On Mobile Health Apps. IEEE Spectrum 2012. Available from: http://spectrum.ieee.org/biomedical/devices/ the-fda-takes-on-mobile-health-apps

[13] European Commission. Healthcare in your pocket: unlocking the potential of mHealth, 2014. Available from: http: //europa.eu/rapid/press-release_IP-14-394_en.doc

[14] Boyer C, Baujard V, Geissbuhler A. Evolution of health web certification through the HONcode experience. Stud Health Technol Inform. 2011;169:53-7.

[15] FDA: Examples of Mobile Apps For Which the FDA Will Exercise Enforcement Discretion. Available from: http://www.fda.gov/MedicalDevices/ ProductsandMedicalProcedures/ConnectedHealth/ MobileMedicalApplications/ucm368744.htm

[16] Lewis TL, Wyatt JC. mHealth and Mobile Medical Apps: A Framework to Assess Risk and Promote Safer Use. J Med Internet Res 2014;16(9):e210 